\title{
Assessment of Sediment and Benthic Macrofauna Distribution at Dar es Salaam Harbour Channel
}

\author{
Benard Mwakisunga1, John F. Machiwa², Harishchandra Bhagwanji Pratap1 \\ ${ }^{1}$ Department of Zoology and Wildlife Conservation Sciences, University of Dar es Salaam, Dar es Salaam, Tanzania \\ ${ }^{2}$ Department of Aquatic Sciences and Fisheries Technology, University of Dar es Salaam, Dar es Salaam, Tanzania \\ Email:sunga2008@gmail.com
}

How to cite this paper: Mwakisunga, B., Machiwa, J. F., \& Pratap, H. B. (2020). Assessment of Sediment and Benthic Macrofauna Distribution at Dar es Salaam Harbour Channel. Journal of Geoscience and Environment Protection, 8, 133-147. https://doi.org/10.4236/gep.2020.83010

Received: February 26, 2020

Accepted: March 28, 2020

Published: March 31, 2020

Copyright $\odot 2020$ by author(s) and Scientific Research Publishing Inc. This work is licensed under the Creative Commons Attribution International License (CC BY 4.0).

http://creativecommons.org/licenses/by/4.0/

\begin{abstract}
Sediment and macrobenthic fauna distribution at Dar es Salaam harbour channel were investigated to attest the influence of sediment grain size distribution and total organic carbon contents on benthic macrofauna dominance and diversity. Sampling campaign was conducted from January to April, 2019 in 25 sampling stations along the channel. Sediment grain sizes ranged between 0.7405 and $0.00273 \mathrm{~mm}$ with an average of $0.0804 \mathrm{~mm}$ classified as medium silt. Sediment distribution showed an onshore-offshore pattern consisting of fine dark clay-silt sediments in the southern part of the harbour close to Mwalimu Nyerere Bridge, medium (sandy) at the harbour and coarse sandy offshore. Five classes of macrofauna were identified with sedentary Polychaetes (Diopatra cuprea) found in tubes and free forms being dominant in most of the sediment types, however more abundant in clay-silt. High species diversity index values were encountered in sediments with medium total organic carbon (TOC) and sediment grain sizes (sand-silt). Apparently, low species similarity indices were observed in all sediment type indicating significant dissimilarities in species composition among sediment grain sizes. Thus, the distribution of benthic macrofauna species along Dar es Salaam harbour channel is strongly influenced by the sediment grain sizes and organic carbon contents in sediments.
\end{abstract}

\section{Keywords}

Sediment Grain Size Distribution, Benthic Macrofauna Diversity and Abundance, Total Organic Carbon Distribution, Dar es Salaam Harbor Channel 


\section{Introduction}

Post 1999 Dar es salaam harbour dredging, the harbour basin experienced a significant sediment deposition at rates between 13 and $43 \mathrm{~cm} /$ year caused by agitated bottom sediments after dredging, change of channel alignment and erosion of sediments at Rasi Makabe and scouring in at the harbour entrance and some areas in the harbour basin (Sanga \& Dubi, 2004). These sediments ultimately were transported by the tidal flow during high tide to the harbour basin. Owing to the fact that sediment grain sizes change predictably in the direction of transport with sediments becoming finer, better sorted and negatively skewed along the transport path (Muzuka \& Shaghude, 2000). Sediment dynamics has a significant influence on the benthic environment including organic matter dynamics and biotic community structures (Krishna, Naidu, Subbaiah, Sarma \& Reddy, 2013; Li, Zhang, Wade, Knap, \& Zhang, 2017).

Hence, the distribution of surface macrobenthic fauna in coastal marine sediments is influenced by various factors including sediment texture, salinity, organic matter content and water movements (Edgar \& Barrett, 2002; Teske \& Wooldrridge, 2003). Water movements such as tidal currents, waves, river discharge greatly govern the deposition and distribution of sediments and organic matter which ultimately determine the distribution and diversity of macrobenthos. Most of the filter feeders occupy the coastal fine sediments with moderate organic matter content and low water velocity (Nanami, Saitoa, Akitab, Motomatsuc, \& Kuwaharaa, 2005; Pedrosa-Pàmies et al., 2015) while suspension feeders are observed in relatively medium to high water velocity that enhances water turbulence.

However, the distribution and diversity of macrobenthos in coastal marine sediments varies greatly with specific ecosystems along and across the coastline. Various studies conducted in Tanzanian coastal waters has showed a considerable variation in species type, diversity and distribution of aquatic biota within and between different coastal ecosystems including mangroves, estuaries, open intertidal and islands ecosystems (Sanga \& Dubi, 2004; Lyimo, Mvungi \& Mgaya, 2008; Saher \& Qureshi, 2011; Mchenga \& Ali, 2013). Thus, requires ecosystem specific investigations of the distribution and diversity of aquatic species in association with their physical-chemical conditions. Little information was available for the distribution of benthic biota especially the macrobenthic fauna from Dar es Salaam harbour channel which is the main effluent receiving area in Dar es Salaam commercial city. The area is located in a sheltered inlet of a narrow bay of seawater, receiving runoffs from the main three rivers in Dar es Salaam city including Msimbazi River in the north, Kizinga and Mzinga Rivers which converge to form Mtoni estuary in the south of the harbour. The main activities at the harbour include loading and unloading of international cargo, ship repairers and other activities of maritime nature, heavy traffic of local fishing and passenger boats and some industrial and city storm water directly discharge in the harbour area. Thus, understanding sediment and benthic macrofauna distribu- 
tion and their relationships in hotspot areas like this became important for the conservation and management of aquatic ecosystems.

\section{Material and Methods}

\subsection{Description of the Study Area}

Dar es Salaam is located between latitudes $6^{\circ} 27^{\prime} \mathrm{S}$ and $7^{\circ} 15^{\prime} \mathrm{S}$ and longitudes $39^{\circ} \mathrm{E}$ and $39^{\circ} 33^{\prime} \mathrm{E}$ (Figure 1), extending about $100 \mathrm{~km}$ from the Mpiji River in the north to Mzinga River in the south (Machiwa, 2010). Dar es salaam harbour is located in a sheltered inlet of a narrow bay protected from free seawater flushing,

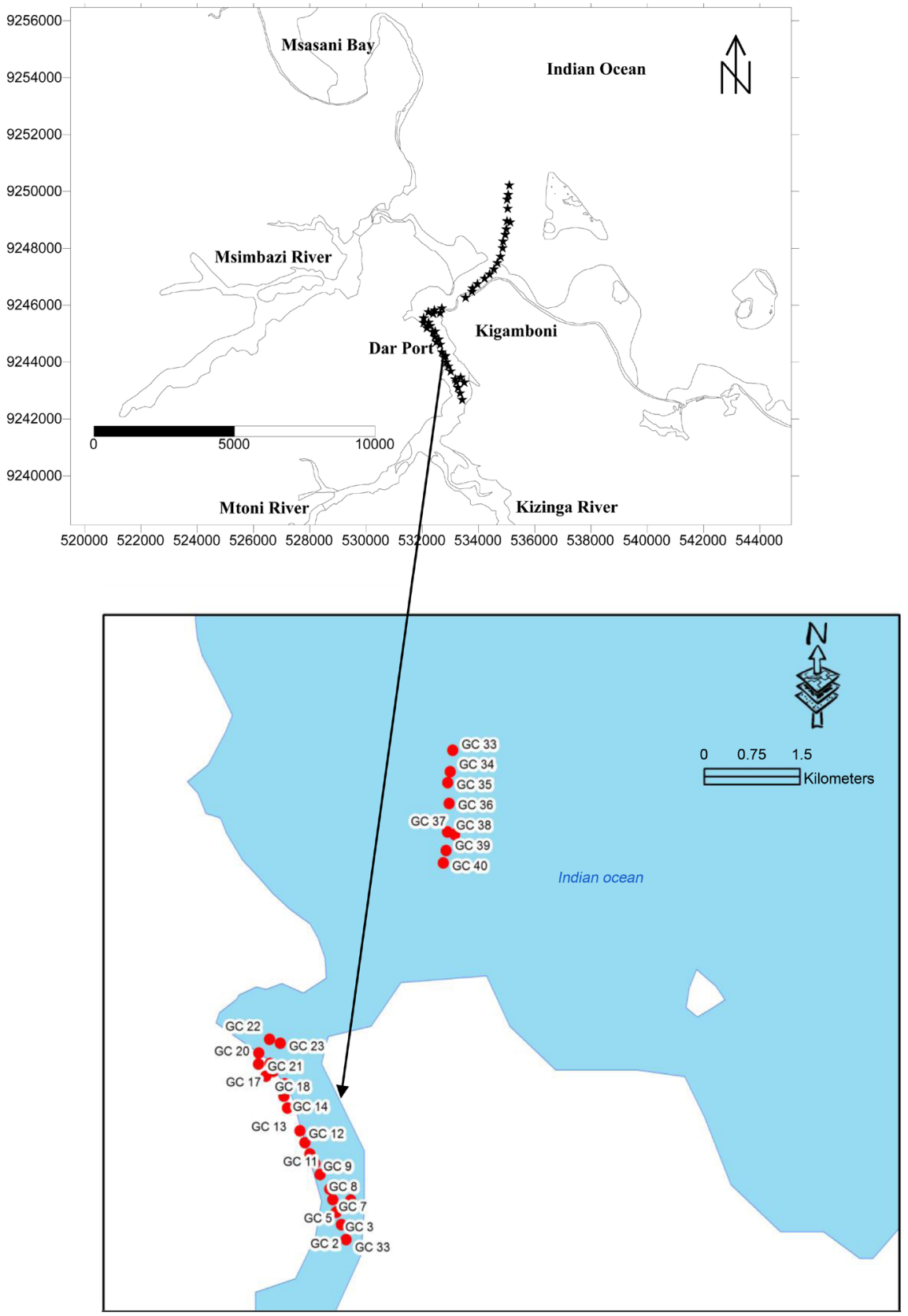

Figure 1. Map of Dar es Salaam coastal marine showing sampling stations. 
the predominant water movement is tidal and seawater waves which influence the direction of localized inshore currents (Machiwa, 1992) and fluvial flows from Mzinga, Kizinga and Msimbazi rivers. These forces in turn govern the deposition and distribution of sediments in the harbour channel.

Based on population growth and growth in economic activities, the study focused on Dar es Salaam Harbour channel which is a main coastal effluent receiving area in Dar es Salaam city. Effluents come from the main three rivers including Kizinga, Mzinga and Msimabazi which are also the major rivers in Dar es Salaam city. The area is also associated with shipping activities and operations, local fishing activities and ferry boat's transportation.

\subsection{Sample Collection and Analysis}

\subsubsection{Sampling}

Sampling campaigns were conducted between February and April, 2019 at Dar es salaam harbour channel. Prior to sampling, a thorough survey was conducted to establish sampling points using Global Positioning System based on the type of sediments, an onshore-offshore pattern of the channel leaving aside the ferry pathway between sampling stations 23 and 40 and the overall spatial coverage of the harbour channel. Sediment and biota sampling were conducted according to EPA (2001) and Goh, Lai, Tan, Yap and Dissanayake (2014). Sediments were collected using a $50 \mathrm{~cm}$ light weight gravity corer then all samples were homogenized before being kept in airtight plastic bags, labeled and sealed then stored in a cool box. After daily field work samples were transferred to the laboratory where were kept in a refrigerator at about $4^{\circ} \mathrm{C}$. All sediment samples were then hydrometrically analyzed at the Soil Mechanics Department of the College of Engineering and Technology, University of Dar es Salaam. The ASTM (2002) standard method for analysis of soil solids by water pycnometer was used.

Grain size distribution data were converted into cumulative weight percentages and used to determine statistical parameters (mean, median, sorting, skewness and kurtosis) using graphic method (Muzuka \& Shaghude, 2000). Results were reported in Phi-values where $\mathrm{Phi}=-\log _{2} D$, where $D$ is particle diameter in millimeters. Equations (1)-(4) were used to determine various statistical parameters.

$$
\begin{gathered}
\text { Mean }=\frac{\varnothing 16+\varnothing 50+\varnothing 84}{3} \\
\text { Sorting }=\frac{\varnothing 84-\varnothing 16}{4}+\frac{\varnothing 95-\varnothing 5}{6.6} \\
\text { Skewness }=\frac{\varnothing 16+\varnothing 84-2 \varnothing 50}{2(\varnothing 84-\varnothing 16)}+\frac{\varnothing 5+\varnothing 95-2 \varnothing 50}{2(\varnothing 95-\varnothing 5)} \\
\text { Kurtosis }=\frac{\varnothing 95-\varnothing 5}{2.44(\varnothing 75-\varnothing 25)}
\end{gathered}
$$

Determination of total carbon and organic carbon in sediments was carried out at the Nelson Mandela African Institution of Science and Technology. Samples were dried at a temperature of $60^{\circ} \mathrm{C}$ and then grinded to fine powder using 
a porcelain mortar and pastel before analysis using C-H-N-S analyzer.

Benthic macrofauna was collected by using Van Veen grab sampler, sieving through $1.0 \mathrm{~mm}$ stainless steel sieve and then preserved in $10 \%$ alcohol in a glass bottle. Specimens were then temporarily stored in the ice cool box before transportation to Kunduchi Marine Biology Laboratory, University of Dar es Salaam for identification. Identification to species level was conducted by using a marine field guide book for Eastern Africa (Raymond, 2002).

\subsubsection{Data Analysis}

\section{Species Dominance and Diversity}

Benthic species dominance, diversity was determined by the use of Shannon Weiver Species diversity index (Equation (5)) and Simpson Index of dominance (Equation (6)).

$$
\text { Shannon Diversity } \operatorname{Index}(H)=-\sum\left(p_{i} \ln p_{i}\right)
$$

where: $p_{i}$ is the proportion of species $i$ relative to the total number of species $\ln p_{i}$ is the natural logarithm of $p_{i}$.

$$
\text { Simpson Index }(C)=\frac{1}{\sum_{i=1}^{s} p_{i}^{2}}
$$

Species similarities among sediment types were assessed using Jaccard similarity formula (Equation (7)) and analyzed for significant differences using one tailed t-test at $95 \%$ confidence level

$$
S_{i j}=\frac{C_{i j}}{C_{i j}+U_{i}+U_{j}}
$$

where:

$i \& j$ are the two sites;

$U_{i}$ is the total number of species counted on site $i$;

$U_{j}$ is the total number of species counted on site $j ;$

$C_{i j}$ is the sum of only the lesser counts for each species found in both sites.

Mean values of abundance and diversity were compared based on grain sizes using one-way ANOVA while species composition similarity in different grain size categories was established using two-tailed one-sample t-test and plotted in a dendrogram using squared Euclidean distances.

\section{Results and Discussion}

\subsection{Sediment and Macrofauna Distribution at Dar es Salaam Harbour}

\subsubsection{Sediment Grain Size Distribution}

The mean sediment grain size showed a varying pattern, with areas close to Mwalimu Nyerere Bridge and proximal to Msimbazi estuary having finest sediments (clay-silt), whereas at the harbour and towards offshore sediment grain size varied from silt-sand to pebbles (gravel) mixed with shells (Plate 1). Over $60 \%$ of the sediment samples were silt and clay, while sand fraction accounted 
for about $35 \%$ of the total sediment samples. The mean grain size of the sediments ranged from $0.74-0.003 \mathrm{~mm}$ with average of $0.08 \mathrm{~mm}$ which according to Udden (1914), was classified as medium silt (Figure 2(a)). There were generally three types of sediments including dark clay-silt (Plate 1(a)) in the south, sandshells mixture at the middle harbour channel (Plate 1(b) \& Plate 1(c)) and coarse sand (gravel) offshore along ship entry area (Plate $1(\mathrm{~d})$ ).

It is common that grain size distributions are generally governed by two main factors; 1) the supply of sediment to the depositional environments, and 2) the hydrodynamic conditions during transport and deposition of the sediments (Taira \& Scholle, 1979 as cited in Muzuka \& Shaghude, 2000). Hence, the sediment grain size distribution pattern observed at Dar es Salaam harbour channel could be attributed to changes in environmental conditions which are fluvial (Mzinga and Kizinga Rivers) and tidal dominated conditions. The low fluvial energy flow

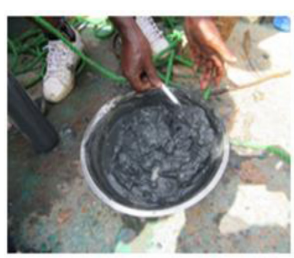

(a)

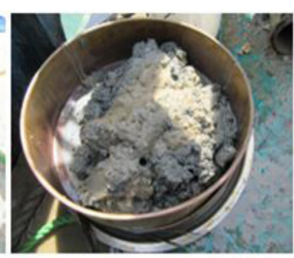

(b)

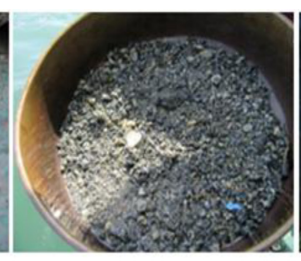

(c)

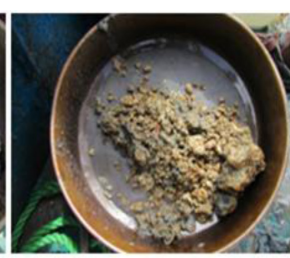

(d)

Plate 1. (a)-(d) Types of sediments along Dar es salaam Harbour channel.

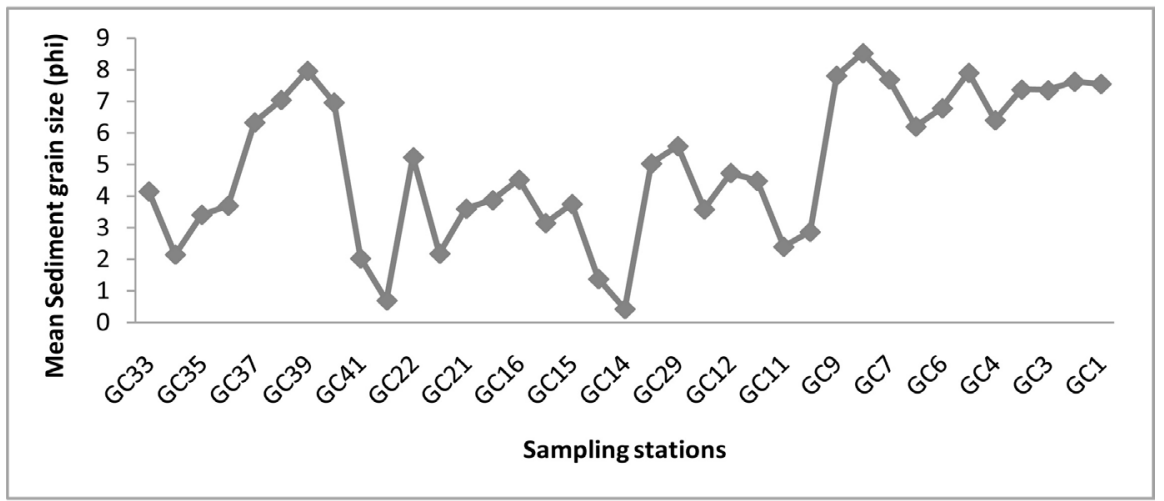

(a)

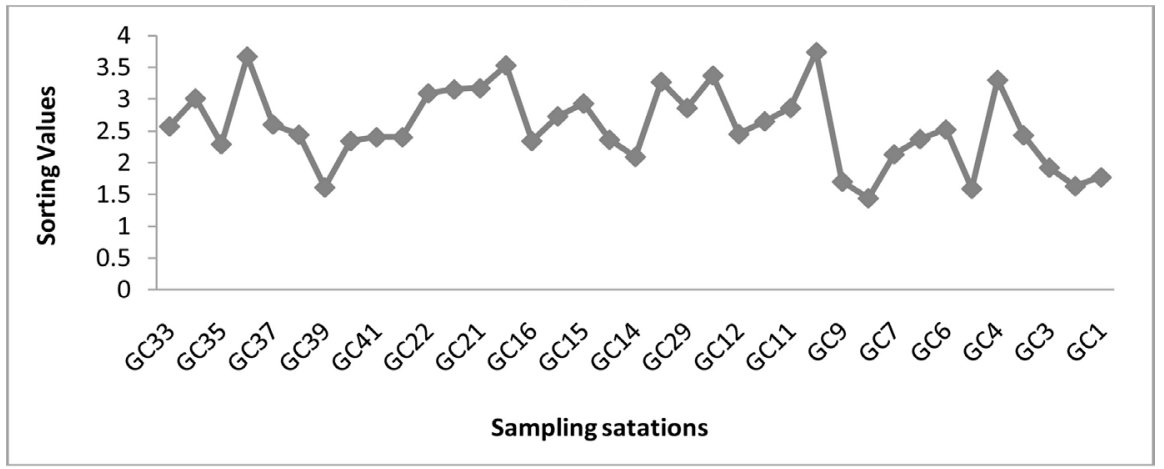

(b)

Figure 2. Sediment grain size distribution at Dar es Salaam harbour Channel. Note: The smaller the Phi value, the coarser the sediments and vice versa. 
accelerates deposition of fine sediments close to Mtoni estuary (close to Mwalimu Nyerere Bridge) in the south while tidal flows influence the distribution of sandy sediments from offshore during high tide associated with scouring in some of the harbour basin sections (Sanga \& Dubi, 2004). Likewise, the effect of previous dredging (Pedrosa-Pàmies et al., 2015) like the 1999 dredge at Dar es Salam harbour might have contributed to deposition of more sands at the harbour than finer sediments that were probably carried away off the harbour channel after re-suspension to the ship entrance area or offshore.

Sediments grain sizes ranged from poorly sorted (sorting values $1.00-2.00$ ) to extremely poorly sorted (sorting values $>4.00$ ). The overall sorting values ranged from 1.29 to 4.08 and averaged $2.55 \pm 0.57$ (Figure 2(b)). Poorly sorted sediments could be attributed to mixing of different materials as attested by the presence of a huge amount of shells and shell fragments.

\subsubsection{Organic Carbon Distribution}

The main sources of organic matter in marine sediments include the active pools of carbon in the oceans, atmosphere, landmasses and carbon pools that cycle on much longer, geological timescale (Pedrosa-Pàmies et al., 2015). However, in coastal marine sediments, organic matter is largely a mixture of terrestrial and marine organic matter and varies along coastal gradients with highest contents inshore than offshore (Krishna et al., 2013; Seki, Tada, Kurokawa, \& Murayama, 2019). In this study, organic carbon content in sediments showed a gradual decrease along onshore-offshore gradient in the harbour channel containing clay-silt, sand and gravel sediments (Figure 3) with medium content in sand-silt. The mean organic carbon contents varied from $1.3 \%$ in coarse sandy (gravel), $1.38 \%$ in fine sand and $1.5 \%$ in clay-silt sediments.

Two-tailed one-sample t-test using GraphPad IntStat package showed significant differences between means of TOC in the three sediment types $(\mathrm{t}=23.544$; $P=0.0018 ; \mathrm{df}=2$; at $95 \%$ confidence level). The highest organic carbon content was observed in clay-silt sediments with a trend of decreasing organic carbon with increasing sediment grain sizes, the phenomenon similarly observed by Barros et al. (2008); Ramaswamy et al. (2008) and Li, Zhang, Wade, Knap and

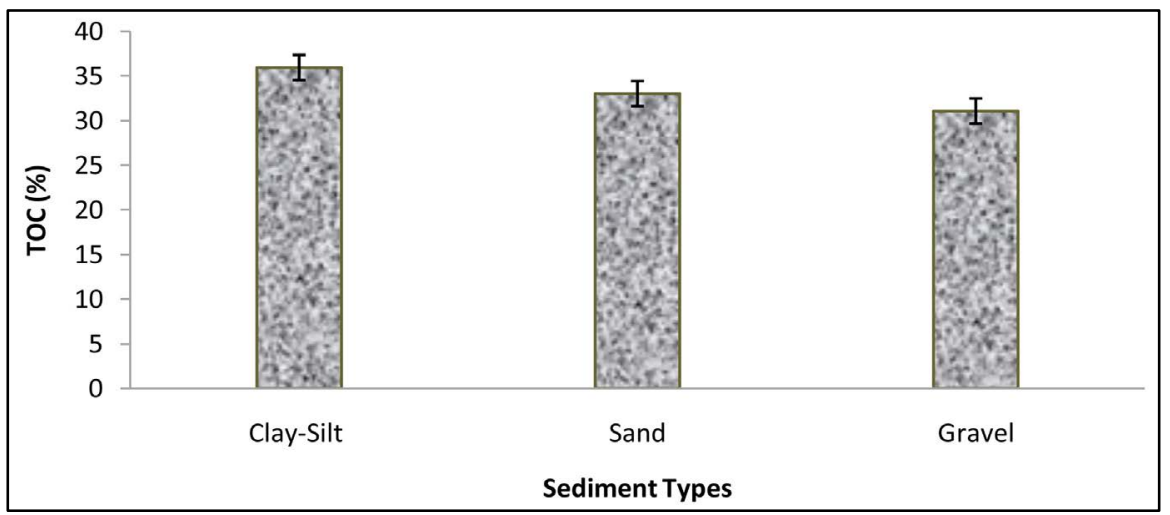

Figure 3. Total organic carbon contents in different sediment types. 
Zhang (2017). Thus, fine sediments contain a higher amount of organic carbon than coarser sediments due to the fact that fine sediments have large surface areas for organic carbon attachment than coarser sediments.

\subsubsection{Benthic Macrofauna Distribution at Dar es Salaam Harbour Channel}

A total of 29 species belonging to six classes of macrobenthic fauna were observed at Dar es Salaam harbour. The main types were the sedentary polychaeta (mostly found in tubes and few in free form), gastropoda, crustacea, Maxillopoda (barnacles), Echnodermata and bivalvia (Figure 4).

Polychaetes were the most highly distributed benthic macrofauna especially Diopatra cuprea, and the highest percentage was found in a mixture of silt-sand sediments which is probably due to higher interstitial spaces for polychaetes burrowing (Musale \& Desai, 2011; Sasikala, Saravanakumar \& Balasubramanian, 2017) and medium contents of organic matter associated with low water velocity in the harbour channel which is an enclosed area like a sheltered bay. However, the observed dark clay sediments close to Mwalimu Nyerere bridge in the south and areas adjacent to Msimbazi river showed absence of benthic macrofauna which is probably due to highly anoxic condition and low interstitial spaces.

\subsubsection{Influence of Sediment Type and TOC on Benthic Macrofauna Distribution}

The dominance of benthic macrofauna at Dar es salaam harbour channel was not influenced by the sediment type or grain size, hence there was no significant variation in species dominance with sediment types, (Oneway ANOVA, $\mathrm{df}=5$, $p=0.5962$ at $95 \%$ probability level). Tube building sedentary polychaetes (Diopatra cuprea) showed dominance in a wide range of sediment grain sizes from clay-silt to coarse sands (Figure 5), thus exhibiting an onshore-offshore distribution with gradual decrease offshore.

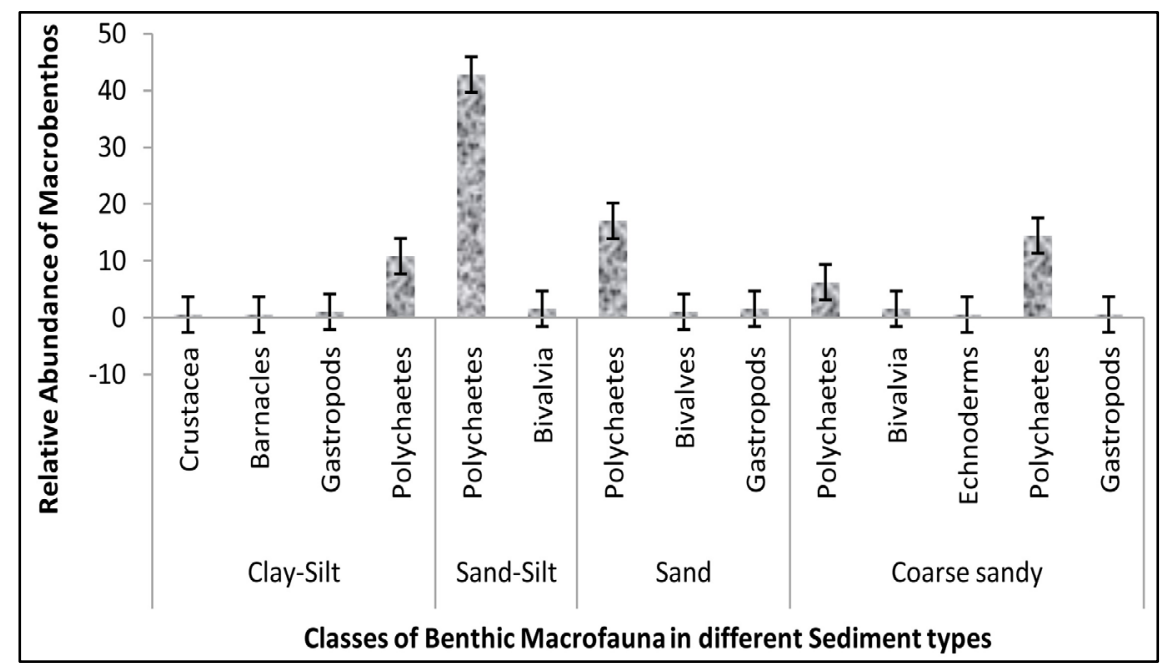

Figure 4. Distribution of benthic macrofauna in different sediment types at Dar es Salaam Harbour. 


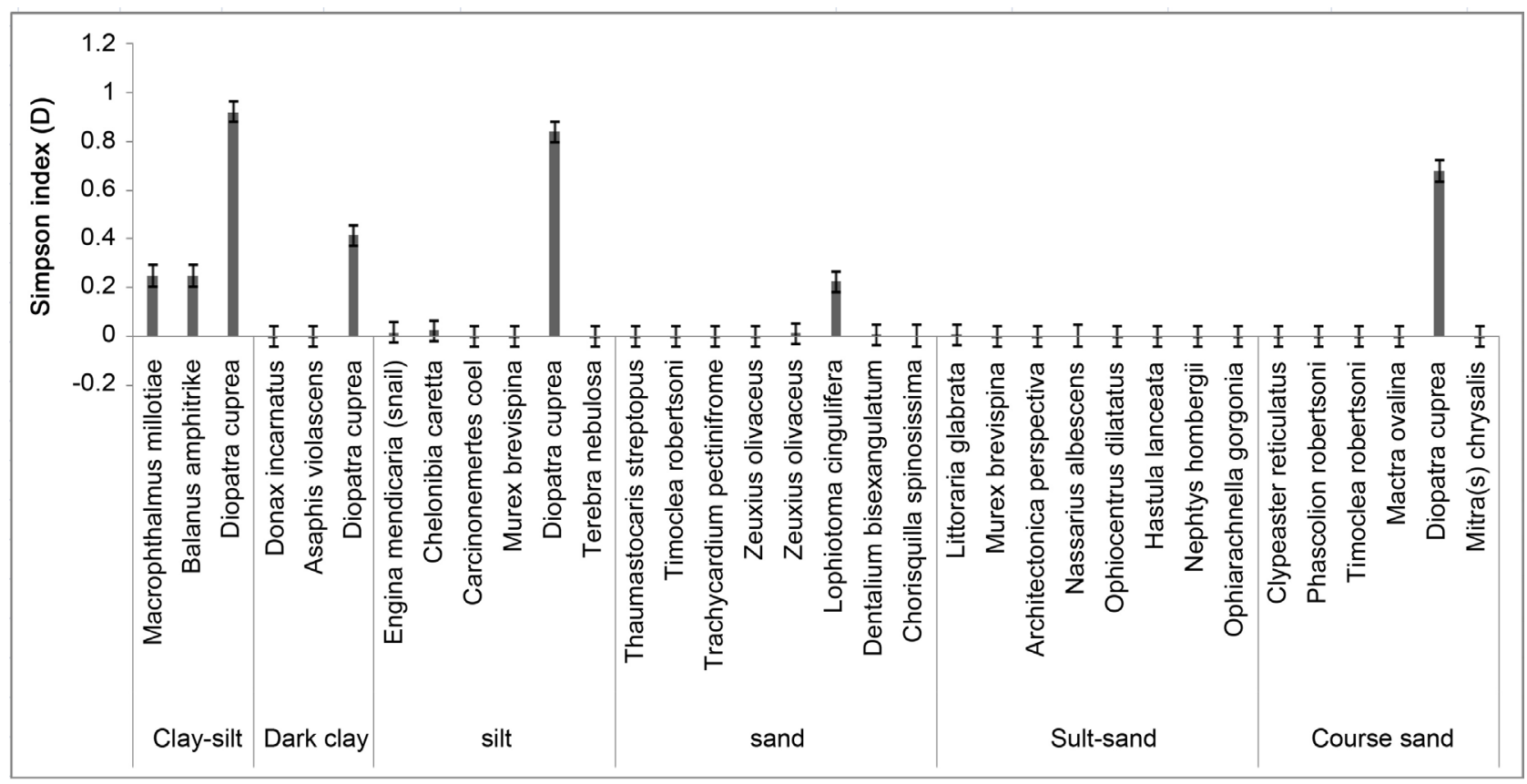

Figure 5. Relationship between species dominance and sediment type at Dar es salaam harbor.

Onshore-offshore distribution trend was similarly observed by Hoey, Degraer and Vincx (2004), where polychaetes (Nephtys cirrosa) showed cosmopolitan distribution over the entire onshore-offshore gradient. However, distribution of D. cuprea over the onshore-offshore gradient at Dar es salaam harbour channel was probably due to its ability of building tubes attached to substratum and have mucus secreting device which helps to protect them from adverse conditions (Anbuchezhian, Rameshkumar, \& Ravichandran, 2009; Waye-Barker, 2015). The highest dominance was observed in the mixture of clay-silt sediments (26\% clay; $74 \%$ silt) with Simpson index of dominance $C=0.92$ while the lowest dominance was in sand-silt sediments ( $81 \%$ sand \& $19 \%$ silt), Simpson index of dominance $(C)$ was 0.27 . Highest polychaetes dominance in the clay-silt sediments supports Mosbahi, Pezy, Dauvin and Neifar (2016), Rengaiyan and Ingole (2017) findings in which Polycheates had the highest assemblage in fine sand and silt-clay sediments along the coastal waters of South-eastern Arabian Sea and in the intertidal zone of Kneiss islands respectively. Medium sized sediments like silt and sand have more interstitial spaces for polychaetes to burrow through and contain a moderate amount of organic matter adequate for polychaetes to acquire energy as deposit feeders (Musale \& Desai, 2011; Sasikala et al., 2017). Similarly, medium sized sediments support algal growth (Chandrasekar, Saravanan, Joevivek \& Sivaperumal, 2012) which act as a primary energy source for macrobenthic fauna. Berke (2012) observed a significant correlation between the abundance of $D$. cuprea and attached algae, acting either as an energy source or in symbiotic life pattern. Deposit feeders also prefer fine sediments with low water velocity to allow detritus accumulation at the bottom (Nanami et al., 2005) on which they sequester organic carbon as an energy source. 
On the other hand, species diversity showed a varying trend with sediment type, Shannon diversity indices $(H)$ varied from 0.2 to 1.7 , the highest diversity was observed in the mixture of fine sand-silt sediments (62\% fine sand \& 38\% silt) with diversity index $(H)=1.7$ in sediment grain sizes ranging between 0.06 and $2.0 \mathrm{~mm}$ (Figure 6). The lowest diversity was in the mixture of sand-gravel (41\% sand, 59\% gravel).

Two tailed one sample $\mathrm{t}$-test $(\mathrm{t}=3.8, \mathrm{df}=5, P=0.0126<0.05)$ indicated a significant difference in macrobenthic fauna species diversity with sediment types.

Similarly, organic carbon content in sediments showed a positive correlation with benthic macrofauna species diversity in the sediments (Figure 7 and Table 1).

Pearson correlation matrix showed negative correlation relationship between sediment grain sizes with species diversity but a positive correlation with total organic carbon (Table 1). The difference in variances of organic carbon and benthic macrofauna diversity indices using One Way Analysis of Variance showed

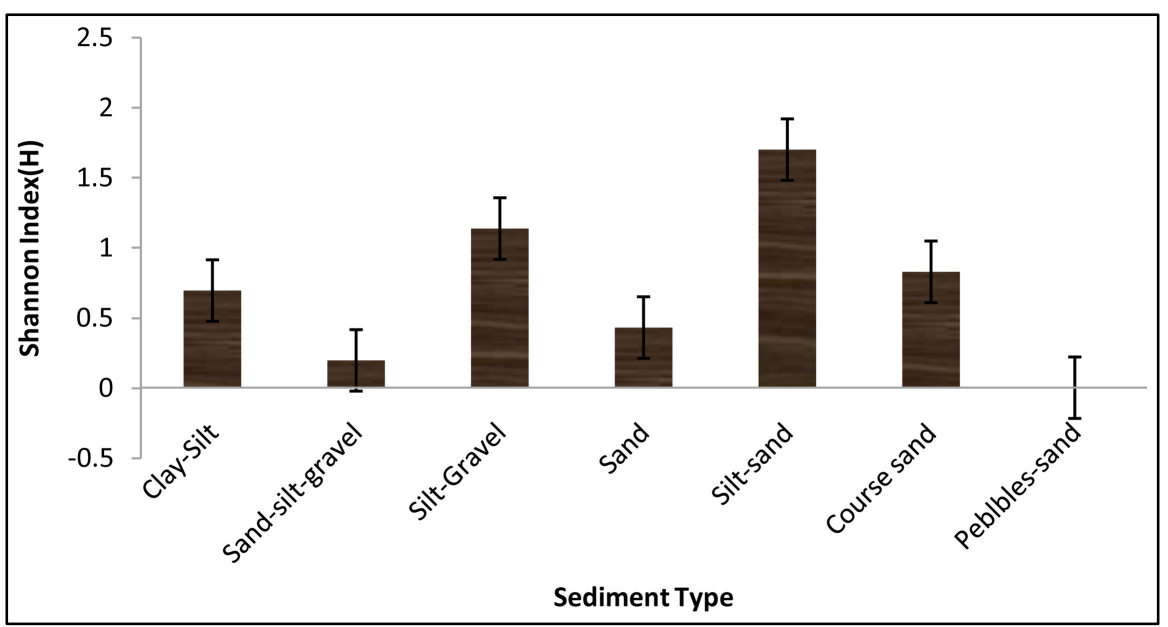

Figure 6. Relationship between Macrobenthic fauna species diversty and sediment types.

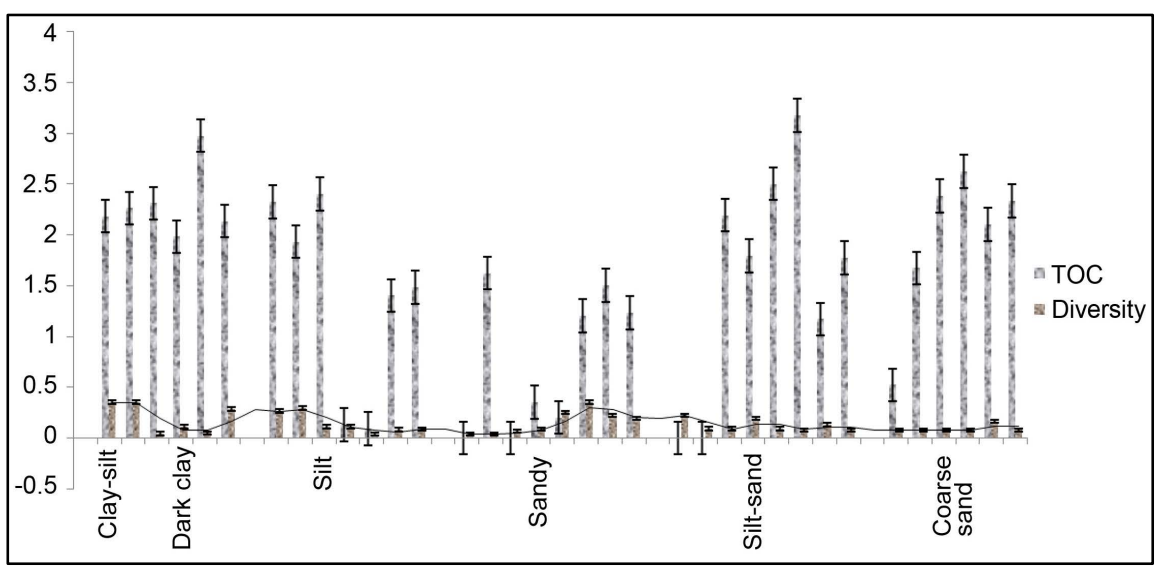

Figure 7. Relationship between Benthic macrofauna distribution with Organic carbon content. 
Table 1. Pearson correlation matrix.

\begin{tabular}{ccccc}
\hline Variable & & Diversity & Grain Size & TOC \\
\hline & Diversity & 1.000 & -0.189 & 0.119 \\
& Grain Size & & 1.000 & -0.123 \\
& TOC & & & 1.000 \\
\hline
\end{tabular}

Table 2. Dissimilarity matrix using squared Euclidean distance.

\begin{tabular}{ccccc}
\hline Cluster & Clay & Silty & Sand & Coarse Sand \\
\hline Clay & 1.000 & 0.000 & 0.001 & 0.003 \\
Silty & & 1.000 & 0.001 & 0.002 \\
Sand & & 1.000 & 0.006 \\
Coarse Sand & & & & 1.000 \\
\hline
\end{tabular}

no significance variation between groups ( $\mathrm{F}=0.1975 ; P=0.6597$ at $95 \%$ confidence level). Higher sediment grain sizes inhabit fewer benthic macrofauna species but the relationship is not linear since it depends on other physic-chemical factors.

Therefore, the observed highest species diversity in silt-sand sediments reveals that water velocity in the area is relatively low to support deposition of fine sand-silt sediments and allows the deposition of detritus on which deposit feeders feed (Vanaverbeke, Merckx, Dgraer \& Vincx, 2011; Waye-Barker, 2015). Fine sands and silt sediments contain adequate organic matter content and are stable substrate to support macrobenthic faunal anchorage and filter feeding mechanism without sediment particles clogging to the feeding apparatus (Joydas \& Damodaran, 2009; Rengaiyan \& Ingole, 2017).

Higher species diversity of macrobenthic fauna in low to medium organic carbon content in the coastal zones has been similarly reported by other studies (Bertrán et al., 2016; Mosbahi et al., 2016; Shou et al., 2017). Increased in organic carbon enhance productivity in deposit feeders however more organic carbon metabolism results in reduced dissolved oxygen in sediments leading in anoxic condition which in turn inhibit the survival of other macrobenthic fauna.

Dissimilarity matrix using Jaccard similarity values (Table 2 ) showed very high dissimilarities in species composition between sediment types with least similarities exhibited by polychaetes ( $D$. cuprea). Nevertheless, two-tailed one-sample $\mathrm{t}$-test showed significant dissimilarities of species composition between sediment types $(\mathrm{t}=4.370 ; \mathrm{df}=6 ; P<0.005 ; \mathrm{SD}=0.2453)$.

Dissimilarities of species composition between sediment types at Dar es Salaam harbour channel was similar to Barros et al. (2008), who observed dissimilarities in macrobenthic fauna at upper Paraguaçu estuarine system but it was contrary to Mosbahi et al. (2016) study which showed significant similarities of macrozoobenthos along the intertidal zone of Kneiss Islands in central Mediterranean Sea. This indicates that, macrobenthic species composition similarities along different types of coastal sediments vary significantly depending on vari- 
ous physic-chemical parameters.

\section{Conclusion}

The main sediment categories at Dar es salaam harbour channel were; clay-silt sediments in the south of the harbour (close to Mwalimu Nyerere Bridge) and at the ship entrance area which were essentially influenced by fluvial discharge from Mtoni estuary and re-deposition of re-suspended fine sediments after preceding dredging associated with discharges from Msimbazi river mouth, waves and local beach currents. Fine to coarse sandy sediments mixed up with fragments of shells at the harbour were due to tidal flows, re-deposition of sandy sediments after previous dredging and probably associated with ship movements.

Sediment grain sizes and organic carbon contents strongly influenced the diversity of macrobenthic fauna species along the harbour channel. However, for better understanding of the governing physicochemical factors of macrobenthic fauna distribution at Dar es salaam harbour channel requires more investigations related to water movements mechanisms with seasons and tidal periods, the historical sedimentology pattern of sediments and chemical parameters.

\section{Acknowledgements}

Sincere appreciation goes to the late Professor Alfred N.N. Muzuka for financial support in the field work through TECHNITAL Ltd, may his soul rest in eternal peace.

\section{Conflicts of Interest}

The authors declare no conflicts of interest regarding the publication of this paper.

\section{Authors' Contribution}

Mwakisunga Benard designed the study, collected the data, analyzed and wrote the manuscript. Prof. Machiwa, J. F and Prof. Pratap, H. B supervised the study and revised the manuscript.

\section{References}

Anbuchezhian, R. M., Rameshkumar, G., \& Ravichandran, S. (2009). Macrobenthic Composition and Diversity in the Coastal Belt of Thondi, Southeast Coast of India. Global Journal of Environmental Research, 3, 68-75.

ASTM (2002). Standard Test Methods for Specific Gravity of Soil Solids by Water Pycnometer. West Conshohocken, PA: ASTM D 854-02.

Barros, F., Hatje, V., Figueiredo, M. B., Magalhaes, W. F., Dorea, H. S., \& Emıdio, E. S. (2008). The Structure of the Benthic Macrofaunal Assemblages and Sediments Characteristics of the Paraguaçu Estuarine System, NE, Brazil. Journal of Estuarine, Coastal and Shelf Science, 78, 753-762. https://doi.org/10.1016/j.ecss.2008.02.016

Berke, S. K. (2012). Biogeographic Variability in Ecosystem Engineering: Patterns in the 
Abundance and Behavior of the Tube-Building Polychaete Diopatra cuprea. Marine Ecology Progress Series, 447, 1-13. https://doi.org/10.3354/meps09568

Bertrán, C., Fierro, P., Encalada, E., Peña-Cortés, F., Tapia, J., Hauenstein, E., \& Vargas-Chacoff, L. (2016). Macrobenthos of the Coastal Budi Lagoon, Southern Chile: Changes Associated with Seasonal Environmental Variation. Brazilian Journal of Oceanography, 64, 239-248. https://doi.org/10.1590/S1679-87592016113306403

Chandrasekar, N., Saravanan, S., Joevivek, V., \& Sivaperumal, M. (2012). Macrobenthic Diversity in Black Sand Enrichment Area along the Coast between Poompukar to Nagoor, India. Journal of Marine Science Research and Development, 2, 111. https://doi.org/10.4172/2155-9910.1000111

Edgar, G. J., \& Barrett, N. S. (2002). Benthic Macrofauna in Tasmanian Estuaries: Scales of Distribution and Relationships with Environmental Variables. Journal of Experimental Marine Biology and Ecology, 270, 1-24.

https://doi.org/10.1016/S0022-0981(02)00014-X

EPA (2001). Methods for Collection, Storage and Manipulation of Sediments for Chemical and Toxicological Analyses. Technical Manual, Washington DC: Office of Science \& Technology.

Goh, B. P. L., Lai, C. H., Tan, L. T., Yap, N. W. L., \& Dissanayake, A. (2014). Handbook of Marine Ecotoxicology Techniques (Vol. 89, pp. 19-29). Singapore: National Institute of Education, NTU \& National Parks Board.

Hoey, G. V., Degraer, S., \& Vincx, M. (2004). Macrobenthic Community Structure of Soft-Bottom Sediments at the Belgian Continental Shelf. Estuarine, Coastal and Shelf Science, 59, 599-613. https://doi.org/10.1016/j.ecss.2003.11.005

Joydas, T. V., \& Damodaran, R. (2009). Infaunal Macrobenthos along the Shelf Waters of the West Coast of India, Arabian Sea. Indian Journal of Marine Sciences, 38, 191-204.

Krishna, M. S., Naidu, S. A., Subbaiah, C. V., Sarma, V. V. S. S., \& Reddy, N. P. C. (2013). Distribution and Sources of Organic Matter in Surface Sediments of the Eastern Continental Margin of India. Journal of Geophysical Research and Biogeosciences, 118, 1484-1494. https://doi.org/10.1002/2013JG002424

Li, X., Zhang, Z., Wade, T. L., Knap, A. H., \& Zhang, C. L. (2017). Sources and Compositional Distribution of Organic Carbon in Surface Sediments from the Lower Pearl River to the Coastal South China Sea. Journal of Geophysical Research and Biogeosciences, 122, 2104-2117. https://doi.org/10.1002/2017JG003981

Lyimo, T. J., Mvungi, F. E., \& Mgaya, Y. D. (2008). Abundance and Diversity of Seagrass and Macrofauna in the Intertidal Areas with and without Seaweed Farming Activities on the East Coast of Zanzibar. Tanzania Journal of Science, 34, 44287. https://doi.org/10.4314/tjs.v34i1.44287

Machiwa, J. F. (1992). Heavy Metal Content in Coastal Sediments off Dar Es Salaam, Tanzania. Journal of Environment International, 18, 409-415. https://doi.org/10.1016/0160-4120(92)90073-D

Machiwa, J. F. (2010). Coastal Marine Pollution in Dar es Salaam (Tanzania) relative to Recommended Environmental Quality Targets for the Western Indian Ocean. Western Indian Ocean Journal of Marine Science, 9, 17-30.

Mchenga, S. S., \& Ali, A. I. (2013). Macro-Fauna Communities in a Tropical Mangrove Forest of Zanzibar Island, Tanzania. Global Journal of Bio-Science and Biotechnology, 2, 260-266.

Mosbahi, N., Pezy, J. P., Dauvin, J. C., \& Neifar, L. (2016). Spatial and Temporal Structures of the Macrozoobenthos from the Intertidal Zone of the Kneiss Islands (Central Mediterranean Sea). Open Journal of Marine Science, 6, 223-237. 
https://doi.org/10.4236/ojms.2016.62018

Musale, A. S., \& Desai, D. V. (2011). Distribution and Abundance of Macrobenthic Polychaetes along the South Indian Coast. Environmental Monitoring Assessment, 178, 423-436. https://doi.org/10.1007/s10661-010-1701-3

Muzuka, A. N. N., \& Shaghude, Y. W. (2000). Grain Size Distribution along the Msasani Beach, North of Dar es Salaam Harbour. Journal of African Earth Sciences, 30, 417-426. https://doi.org/10.1016/S0899-5362(00)00027-0

Nanami, A., Saitoa, H., Akitab, T., Motomatsuc, K., \& Kuwaharaa, H. (2005). Spatial Distribution and Assemblage Structure of Macrobenthic Invertebrates in a Brackish Lake in Relation to Environmental Variables. Estuarine, Coastal and Shelf Science, 63, 167-176. https://doi.org/10.1016/j.ecss.2004.11.004

Pedrosa-Pàmies, R., Parinos, C., Sanchez-Vidal, A., Gogou, A., Calafat, A., Canals, M., Bouloubassi, I., \& Lampadariou, N. (2015). Composition and Sources of Sedimentary Organic Matter in the Deep Eastern Mediterranean Sea. Biogeosciences, 12, 7379-7402. https://doi.org/10.5194/bg-12-7379-2015

Ramaswamy, V., Gaye, B., Shirodkar, P. V., Rao, P. S., Chivas, A., Wheeler, D., \& Thwin, S. (2008). Distribution and Sources of Organic Carbon, Nitrogen and Their Isotopic Signatures in Sediments from the Ayeyarwady (Irrawaddy) Continental Shelf, Northern Andaman Sea. Marine Chemistry, 111, 137-150.

https://doi.org/10.1016/j.marchem.2008.04.006

Raymond, M. D. (2002). Field Guide Book to the Seashores of Eastern Africa and the Western Indian Ocean Islands (3rd ed.). SIDA.

Rengaiyan, P., De, K., \& Ingole, B. (2017). Polychaete Assemblage Driven by Substrate Composition along the Coastal Waters of the South-Eastern Arabian Sea. Regional Studies in Marine Science, 16, 208-215. https://doi.org/10.1016/j.rsma.2017.09.004

Saher, N. U., \& Qureshi, N. A. (2011). Diversity and Distribution of Mangrove Crabs in Three Intertidal Areas of Balochistan, Pakistan. Pakistan Journal of Marine Sciences, 20, 27-36.

Sanga, I. P. L., \& Dubi, A. M. (2004). Impact of Improvement of the Entrance Channel on the Rate of Sedimement Deposition into the Dar es salaam Harbour. Western Indian Ocean Journal of Marine Sciences, 3, 105-112. https://doi.org/10.4314/wiojms.v3i2.28454

Sasikala, V., Saravanakumar, A., \& Balasubramanian, T. (2017). Spatial and Temporal Distribution of Macrobenthos in Point Calimere of Southeast Coast of India. Indian Journal of Geology and Marine Sciences, 46, 377-384.

Seki, A., Tada, R., Kurokawa, S., \& Murayama, M. (2019). High-Resolution Quaternary Record of Marine Organic Carbon Content in the Hemipelagic Sediments of the Japan Sea from Bromine Counts Measured by XRF Core Scanner. Progress in Earth and Planetary Science, 6, 1-12. https://doi.org/10.1186/s40645-018-0244-Z

Shou, L., Liao, Y., Tang, Y., Chen, J., Jiang, Z., Gao, A., \& Chen, Q. (2017). Seasonal Distribution of Macrobenthos and Its Relationship with Environmental Factors in Yellow Sea and East China Sea. Chinese Journal of Oceanology and Limnology, 36, 1-11. https://doi.org/10.1007/s00343-018-6271-1

Teske, P. R., \& Wooldrridge, T. H. (2003). What Limits the Distribution of Subtidal macroBenthos in Permanently Open and Temporarily Open/Closed South African Estuaries? Salinity vs Sediment Particle Size. Estuarine, Coastal and Shelf Science, 57, 225-238. https://doi.org/10.1016/S0272-7714(02)00347-5

Udden, J. A. (1914). Mechanical Composition of Clastic Sediments. Geological Society of America Bulletin, 25, 655-744. https://doi.org/10.1130/GSAB-25-655 
Vanaverbeke, J., Merckx, B., Dgraer, S., \& Vincx, M. (2011). Sediment-Related Distribution Patterns of Nematodes and Macrofauna: Two Sides of the Benthic Coin? Marine Environmental Research, 71, 31-40. https://doi.org/10.1016/j.marenvres.2010.09.006

Waye-Barker, G. A. (2015). The Effects of Marine Sand and Gravel Extraction on the Sediment Composition and Macrofaunal Community of a Commercial Dredging Site (15 Years Post Dredging). Marine Pollution Bulletin, 99, 207-215.

https://doi.org/10.1016/j.marpolbul.2015.07.024 